\section{Research Article}

(c) 2021 Hamdah Abdullah Alfaraidy. This is an open access article licensed under the Creative Commons Attribution-NonCommercial 4.o International License (https://creativecommons.org/licenses/by-nc/4.o/)

\title{
Exploring Employed Women's Perceptions of Leadership in the Light of a Leadership Program in Saudi Arabia
}

\author{
Hamdah Abdullah Alfaraidy \\ Assistant Professor of Social Work, \\ Princess Nourah Bint Abdulrahman University, \\ Saudi Arabia
}

DOI: https://doi.org/10.36941/jesr-2021-0o28

\begin{abstract}
The present research paper aims at exploring the expectations and perceptions of leadership among Saudi employed women who accomplished a leadership development program "Qiyadat" offered by MiSK Foundation. The author designed a questionnaire of eight domains to examine the participants' perceptions of the leadership program content, required leadership competencies, leadership challenges, support, program success requirement, as well as understanding and implementing the Saudi Vision 2030. The sample consisted of 6o employed women who have attended a leadership development program offered by Misk Foundation in the academic year 2019/2020. Following a descriptive-analytical research design, the author administered the instrument to collect data and discuss the results. The results showed that the participants have high perceptions of leadership due to the leadership development program offered by Misk Foundation. Additionally, there was a positive correlation between the participants' perceptions of leadership and the seven variables of the questionnaire (i.e., the leadership program content, leadership competencies, leadership challenges, sources of support, program success requirements, understanding Saudi Vision 2030, and execution of Saudi Vision 2030). There were no statistically significant differences between the participants in their perceptions of leadership in the light of the women's leadership program offered by Misk Foundation according to the years of experience. Thus, it is highly recommended that public and private sectors support women in the development of leadership, address their needs, and overcome challenges facing their empowerment and gender equity.
\end{abstract}

Keywords: Women's leadership, perceptions, leadership programs, Saudi Arabia

\section{Introduction}

The Kingdom of Saudi Arabia is the largest country in the Gulf region. According to General Authority for Statistics for the year 2019 the total population was 34 million, of which 14.5 million are female. Its population is also quite young with over half the population under 25 years old. The Saudi government, as well as the entire Saudi society, has witnessed dramatic political, economic, and social changes. These changes make women's participation in the entire development process, including occupying leading positions a must. These positions require equipping women with specific skills that enhance their capabilities and performance considering the conservative nature of the Saudi society; therefore, public and private institutions, as well as individuals, have become more concerned with offering and 
encouraging women's participation in leadership programs. The change in women's roles might be attributed to the belief that it is becoming essential to increase women's participation in social development to achieve goals and to ensure better social and economic productivity (Al Ghamdi, 2016).

Due to the severe decline in oil prices, the Saudi government encountered great challenges and decided to implement a general overhaul known as the Saudi Vision 2030. The vision is introduced and managed by the Council of Economic and Development Affairs (2016). It focuses on three main themes: A vibrant society, a thriving economy, and an ambitious nation. It relies on the efforts of organizations and individuals to be properly executed; therefore, the vision exhibits great concern for women as a major part of society and is greatly encouraged to participate in the execution of the vision. It is aimed that by 2030 women's participation in the workforce will reach $30 \%$. Thus, it seems important to ensure the availability and suitability of the educational and training programs introduced for women to ensure their legitimate adoption of these changes, as well as their proper participation in the execution of the vision (Almansour \& Kempner, 2016; Al-Shamrani, 2015).

Women in Saudi Arabia have been under great focus and attention by the government to participate in different life aspects, including leadership positions. Therefore, the empowerment of Saudi women in various fields has become a necessity to fulfill leadership roles. However, this expansion in the women's responsibilities in the workforce is not sufficient as it continues to be one of the lowest worldwide, and Saudi women are under-represented in leading academic positions (AlAhmadi, 2011). Almenkash, Abdulaziz, Shaman, Haijan, and Dagsh (2007) point out that Saudi women encounter challenges in the workforce such as indefinite organizational policy regarding women and men promotion, poor coordination between men and women sections within organizations, weak participation in strategic plans and decision-making, and exclusion of women from the organizational chart and some policies. These barriers reduce women's authority and empowerment and limit Saudi women's chance to achieve their leadership potential.

\subsection{Statement of the Problem}

A great deal of concern has been given recently to Saudi women who could prove competence and share the assigned obligations when they participate in the fields of education, medicine, and politics. For example, women's education preceded other appearances in different fields; women outnumbered men in general education reaching 3,043,875 (Ministry of Education, 2017). Similarly, Saudi women managed to participate in politics through voting and running in the Municipal Council (one of the highest political hierarchies in the Kingdom of Saudi Arabia) during December 2015 political elections for the first time. Thirty women were appointed as members of the council, which was considered a major step for women in Saudi Arabia (Al Ghamdi, 2016).

Mohammed bin Salman bin Abdulaziz Foundation (MiSK) in Saudi Arabia provides leadership training to Saudi young men and women to promote their leadership skills and to become effective leaders in the workplace. The four-day program "Qiyadat" (i.e., leaders) offers leadership training all over the Kingdom of Saudi Arabia to encourage pursuing education and leadership development and to achieve Saudi Vision 2030 by increasing female contribution to national development. To this end, the program applies modern methods of training, such as intensive practical workshops, field visits, and meetings to empower women to have a positive influence in their institutions. Moreover, the program focuses on the modern concept of leadership, strategic planning, problem analysis, and decision making, mental and emotional intelligence, as concepts and levels of dispute. Applicants should be Saudi nationals, currently employed in administrative/leadership positions, and completed the registration form successfully (Mohammed bin Salman Foundation (Misk), 2018).

Despite previous research in women's leadership in Saudi Arabia (Al-Olyan, 2016; Al-Shamrani, 2015), little effort has been exerted to define women's leadership roles clearly and the barriers they encounter in achieving the Saudi Vision 2030. Walton (2012) points out that measuring and assessing women's leadership roles is difficult because leadership is a vague concept and the efforts to develop it varY widely in their methods and tackle many leaders; besides program results are often evaluated 
indirectly. Although various organizations provide leadership development programs to prospective leaders, traditional leadership programs have failed to meet women's needs (Ely, Ibarra, and Kolb, 2011). Hence, the present research seeks to fill in this gap by exploring the perceptions and expectations of Saudi employed women.

\subsection{Questions}

The study seeks to answer the following questions:

1. What are the participants' perceptions of leadership in the light of the women's leadership program offered by Misk Foundation?

2. Is there a correlation between the participants' perceptions of leadership and the seven domains of the questionnaire (the leadership program content, leadership competencies, leadership challenges, sources of support, the program success requirements, understanding the Saudi Vision 2030, and execution of Saudi Vision 2030)?

3. Are there statistically significant differences between the participants in their perceptions of leadership in the light of the women's leadership program offered by Misk Foundation according to the years of experience?

\subsection{Objectives}

The study aims to:

1. Identify the participants' perceptions of leadership in the light of the women's leadership program offered by Misk Foundation.

2. Determine the correlation between the participants' perceptions of leadership and the seven variables of the questionnaire (the leadership program content, leadership competencies, leadership challenges, sources of support, the program success requirements, understanding the Saudi Vision 2030, and execution of Saudi Vision 2030).

3. Define the differences between the participants in their perceptions of leadership in the light of the women's leadership program offered by Misk Foundation according to the years of experience.

\subsection{Significance}

The study has both practical and academic contributions. Its findings help inform decision-makers, partners, funders, and stakeholders upgrade leadership programs to empower women in achieving development at the national level. More initiatives and programs will be implemented by the government and partners to enhance gender equality and female empowerment. The potential outcomes include increasing the awareness of gender equity and sustaining women empowerment. As for the scientific and academic contributions, the study offers a reliable instrument for collecting data to help authors assess leadership programs. With the increasing empowerment of women, more empirical research should be conducted to evaluate the outcomes of leadership programs in various contexts. Hence, the present study contributes to the emerging research by investigating employed women's expectations, experiences, and perceptions on these programs in the Saudi context, in particular, and the international contexts, in general, by providing a clear picture about their level of perceptions of leadership.

\subsection{Limits}

The study was delimited to a sample of $(N=60)$ employed women who attended a leadership development program offered by Misk Foundation. It was delimited to the academic year 2019/2020. It explored women's perceptions of leadership in the Saudi context. 


\section{Review of the Literature \& Theoretical Framework}

Evaluating leadership programs can be drawn from two theoretical frameworks including the Resource Dependence Theory (RDT) and the Social Capital Theory. As for the RDT developed by Pfeffer and Salancik $(1978$; 2003), leadership training is essential to limit organizational dependence on external factors and develop human potentials. The RDT provides authors with a framework to perceive organizational leadership as a development in which organizations and leaders are co-dependent on crucial resources. Organizations can eliminate risks by being proactive in training their human resources (Pfeffer \& Salancik, 1978;2003).

Organizations are idiosyncratic bodies with valuable leadership assets. Therefore, improving social capital resources impacts the organization's operation and the leaders' functions. Akingbola (2013) believes that social capital is useful for organizations as this theory emphasizes the importance of social networks, cooperation, and knowledge sharing. Thus, leaders need social capital resources to function well and help organizations promote social capital development for increased economic growth.

Other theories can be the basis for the present study. The Social Identity Theory (SIT) (Tajfel \& Turner, 1985) explains the process behind the perception and ideal relationship between leaders and followers. When a leader is the best fit with a follower's perception, the leader will be accepted, which enhances the follower's chance to engage in high-performance behaviors. Additionally, the psychology theory can help with interpreting the mechanism by which leaders and followers can work together to produce high performance. This issue has shifted focus on followership and how followers' perceptions of leadership impact their performance (Ehrhart \& Klein, 2001). These models are based on the belief that effective leadership positively influences leaders' behaviors and followers' information processing.

\subsection{Women empowerment in the light of Saudi Vision 2030}

The Saudi government has adopted Vision 2030 to empower women by developing their roles instead of focusing on enhancing their right to education and employment. This goal has been highlighted to achieve the strategic objectives of development. Globalization, economic growth, and social developments in Saudi Arabia could not be achieved without a comprehensive improvement in the global society. The Saudi strategic plan aspires to recruit qualified women into leading positions in the public and private sectors. Saudi women have recently held positions, such as deputy minister, university president, Shura Council consultants, and board members of chambers of commerce (Al-Ahmadi, 2011).

The Kingdom has achieved significant improvements in the education gaps of $10 \%$ to $12 \%$ by closing $99 \%$ of its education gender gap to eliminate this gap in leadership positions. This is due to the increasing number of higher institutions across Saudi Arabia over the past decade, which enhances women's opportunities to access high education (Ministry of Education, 2017). In 2009, King Abdullah bin Abdul-Aziz granted Saudi women the freedom to be leaders and announced the first woman to be the Deputy Minister of Education. As a result, a fundamental change in government policies has begun to grant women more leading positions in Saudi Arabia. For example, in 2015, the Saudi Shura Council has appointed 30 women members and a hundred women applied for the first elections, with only 37 women holding seats (Al-Sudairy, 2017).

\subsection{Women and leading academic positions}

Howard (2019), Jones and Solomon (2019), and Poltera (2019) report that women around the world still experience challenges of leadership related to gender equality, such as equitable salaries, sexual harassment, racial exclusion, poverty, political violence, socio-economic instability, cultural diversity, corruption, and health challenges, which are influenced by age, race, and ethnicity. Hopkins, O'Neil, Passarelli, and Bilimoria (2008) and Hacıfazlıoğlu (2010) found out that women in leading academic positions in Turkey and the United States of America experience challenges in leadership, fitting in 
with the institution, and maintaining the balance between family and career. To overcome these challenges, leadership development for women should focus on specific aspects of coaching, mentoring, networking, experimental learning, and career planning. Martin, Jahani, and Rosenblatt (2016) state that gender equality is essential for creating a stable society, as addressed by the World Academy for the Future of Women (WAFA). Even though the WAFA believes that gender equality is essential for a stable society.

Women are still a long way from competing with men in the workplace and social sectors of life. Reports showed that women in the presidency office in higher education make up $26.4 \%$ and this portion slowed down gradually since the 1990 os (Cook, 2012). Ibid (2012) notes that women followed a traditional career path toward leading academic positions, unlike men who are likely to come from a nonacademic position on campus, and there is a biased strategy at work; where men are hired for their potential and women are hired for their achievements. Reports concerning women's leadership in higher education in Saudi Arabia revealed that Princess Nourah Bint Abdulrahman University is the highest in terms of leading positions with $(3 \%)$ in the position of dean/director at and (9.3\%) holding the position of vice/ deputy. There are 12 women vice deans in other Saudi universities, such as King Abdullah University of Science and Technology or vice (deputy) deans for women's sections (campuses), such as King Faisal University and King Saud University (Ministry of Education, 2017).

Saudi women have made great progress in higher education. For example, female lecturers increased from 4700 to 19,600 in $2008 / 2009$ compared to an increase of 7200 to 48,800 in male lecturers over the aforementioned period (Al Alhareth, Al Dighrir, and Al Alhareth, 2015). Although education in Saudi Arabia is gender-segregated, and women have a reasonable proportion of higher education leadership positions in female university sections, they tend to hold lower-level positions (Alomair, 2015). This issue might be due to the cultural conventions in Saudi society and legislative restrictions that women have been prevented from holding leading positions in Saudi Arabia.

\subsection{Barriers to leadership}

Many factors contribute to the underrepresentation of women in leadership positions. Kauser and Tlaiss (2011) and Metcalfe (2006) mention cultural practices that control women's right to work and gender role expectations. For example, the traditional organizational hierarchies benefit men by providing them with access to "Wasta"; important interpersonal connections and family networks. However, women have to depend on male family members to facilitate wider social networks. Academic women in Saudi Arabia encounter many barriers in the workplace. Hodges (2017) identifies these barriers as social, religious, cultural, and organizational. Women suffer from "the lack of mobility; salience of gender stereotypes; gender discrimination in the workplace; limited opportunities for growth, development, and career advancement; excessive workload caused by a lack of family-work balance; gender-based challenges related to dealing with pregnancy" (Al-Asfour, Tlaiss, Khan \& James, 2017, p. 184).

Alotaibi, Cutting, and Morgan (2017) categorize barriers that Saudi women face into structural and cultural. As for the structural level, the rate of unemployment among Saudi women in 2008 was $26.9 \%$ and most of the job opportunities were in education and health. Women have limited chances to work in engineering and politics. Moreover, the private sector prefers men over women due to social norms and extra costs for creating women-friendly environments. Cultural and social barriers include women's mobility restrictions and the stereotypical belief that women's main role is in the family according to Islamic beliefs. Similarly, Abalkhail (2017) investigated the challenges and opportunities for Saudi women in higher education by interviewing 22 women in two higher education institutions. The findings showed that despite holding higher qualifications and stronger experience than their male counterparts, the participants thought that men were given priorities in recruitment processes for leadership roles due to cultural and religious issues. This impedes women from contributing to strategic meetings and limits their access to important resources. The participants also emphasized the role of training and support from family members.

Many studies have investigated female leaders in academic contexts. For example, Dannels et al. 
(2008) evaluated the effect of the ELAM program of leadership by comparing three groups of participants using the pre-/posttest methodology and longitudinal structure. A group of ELAM cohorts was compared to a control group of women who applied to take part in this leadership program but were not accepted and a group of women from the Association of American Medical Colleges (AAMC) Faculty Roster. Data were collected in 2002, and the follow-up data were gathered in 2006. The authors considered 16 leadership indicators: Administrative leadership attainment, full professor academic rank, leadership competencies and readiness, and leadership aspirations and education. The results showed that ELAM participants scored higher than AAMC and the non-groups on all indicators except for one indicator (aspiration to leadership outside academic health centers) in which they scored higher than the AAMC group. Statistical significant results were found for 12 indicators, which revealed the effectiveness of the ELAM program in leadership behaviors and career progression.

Al-Ahmadi (2011) surveyed 16o female leaders to examine the challenges that women leaders encounter in government sectors in Saudi Arabia. The results showed that the main challenges include structural challenges, lack of resources, and lack of empowerment. It was also found that cultural and personal challenges were ranked last, unlike common perception. Hamdar, Massoud, and Farha (2013) explored the factors that influence women's behavior and performance at leading positions and the challenges that hinder women from reaching the top positions in organizations. A survey was administered to a sample of Lebanese managers and employees to assess their attitude and behavior towards Lebanese female leadership and to examine factors that lead to the glass ceiling and discrimination against women in leadership positions. In addition, NcNae and Vali (2015) conducted a case study to explore the experiences of women leadership and the effect on their leading roles in higher education in Papua New Guinea. The results showed that women faced organizational challenges that limit their potentials. The relationship between networks and agency and cultural support were found to be helping factors for women's access to leadership roles.

Al Ghamdi (2016) conducted a quantitative study to examine the perception and effect of leaders' sense of psychological empowerment for female leaders on their administrative creativity in 6 public universities in Saudi Arabia. The sample consisted of (377) academic male and female leaders at Saudi universities. The results indicated five predictors of the perceptions of administrative creativity for academic female leaders. There was a high positive impact of psychological empowerment on administrative creativity. Therefore, administrative creativity is greatly influenced by psychological empowerment for academic female leaders. Likewise, Krystal and Brue (2016) conducted a study using the phenomenological method to explore the experiences of 7 alumni of a "women's-only" leadership program. Through semi-structured interviews, the authors found that the learning elements were the most beneficial in enhancing individuals' leadership role. Emerging research themes included perceptional and personal agency changes within participants. The relational model methods, action learning techniques, interconnectedness, philosophical leadership development were found to be the most effective in leadership development.

Hodges (2017) explored the challenges that encountered women's advancement in Saudi Arabia by examining their experiences of becoming leaders and influences that affect their leadership practice. The authors interviewed 25 professional women in Saudi Arabia. The findings showed that the challenges included social, religious, cultural, and organizational factors. Women's relationship to self, others, place, and work shape their perception and experience of leadership. The findings suggested the reformation of policies to eradicate inequalities. Similarly, Krause (2017) explored the effect of stereotypical views of female behavior on women aspiring for leading positions in academic institutions. The qualitative study was conducted by interviewing participants on their understanding of leadership and its styles, influence on the workplace, and experiences in their leadership roles. The findings showed that women's roles as female leaders were influenced by a biased traditionally masculine role of leadership. These stereotypical views of female behavior did not greatly impact their successful careers.

Hamdan and Al Hattami (2018) examined the effect of a leadership program on university students' perception of leadership skills. The authors conducted a survey that included seven dimensions: Communication, planning, teamwork, decision-making, controlling, motivation, and 
evaluation. The sample included 36 randomly selected female students who participated in a two-day leadership program at the University of Dammam. The findings showed that the program developed participants' perceptions of leadership skills. The KPMG Women's Leadership Study (2019) performed a quantitative 20-minute online survey among 3,014 women in the United States (604 college women and 2,410 working women). The participants were college women currently enrolled in part-time or full-time in advanced degree program and working women; or, who are college educated and currently working full-time. The results revealed that $64 \%$ of the participants aspired to be a senior leader, and $56 \%$ of them aspired to be on the board of a company or organization. However, they were hesitant about taking a leadership role. Moreover, they reported difficulty envisioning leadership in their future. About $59 \%$ of the participants indicated that they find it hard to see themselves as leaders. Hence, the study highlighted the important role that encouragement plays in overcoming this hesitation.

Alwazzan and Al-Angari (2020) reviewed women's leadership in academic medicine and the factors that impact women's roles in leadership programs. After analyzing 40 studies, it was found that women's leadership emergence was hindered by institutional requirements including research productivity and educational credentials. On the other hand, women's enactment of leadership was limited by a lack of policy implementation. Leadership programs had a positive effect on women's enactment of leadership and medical schools' cultures.

The review of the literature shows that attention is lacking to examine the perceptions and expectations of leadership programs for female leaders in Saudi Arabia. Although there are few studies at the national level in Saudi Arabia that have investigated female leadership empowerment, a gap exists as most of them are limited to women who took leading positions. For example, Al-Ahmadi (2011), Abalkhail (2017), and Alotaibi et al. (2017) addressed the challenges that face Saudi female leaders in the Saudi academic contexts. Moreover, Al Ghamdi (2016) and Hamdar et al. (2013) explored the factors that influence female leaders' perceptions of leadership roles. However, none of these studies have measured specifically the effect of woman leadership programs on women's attitudes and expectations that strongly affect their leadership empowerment. Like Dannels et al. (2008), the present study investigates the perceptions and expectations about leadership among Saudi employed women who completed a leadership development program.

\section{Methodology}

\subsection{Research Design}

Due to the descriptive nature of the study, it followed the analytical descriptive design. The author utilized a questionnaire to collect data regarding the population's demographics, the correlations and differences in perceptions, and the expectations of leadership among the participants. A questionnaire was applied because it is the most appropriate tool for obtaining opinions, beliefs, attitudes, and it enables some generalizations regarding the population (Creswell, 2013).

\subsection{Population and Sampling}

The population of the study covered employed Saudi women. The sample consisted of one group $(N=$ 6o) who were purposefully selected of the ones who finished a leadership program offered by Misk Foundation. The sample was adjusted in terms of demographic factors: Age, level of education, and years of experience. These demographic factors have been utilized to adjust the sample, not for statistical analysis. By signing the informed consent, the participants indicated a clear understanding of what participation involved, including the anonymity. The participants and Misk Foundation were also provided with complete contact details for the author to help discuss any issue associated with participation. Data collection was conducted in the first semester of the academic year 2019/2020 by emailing a questionnaire to 85 participants. The total number of returned completed questionnaire forms was 6o. The distribution of the research sample is presented in table 1 . 
Table (1): The distribution of the research sample $(N=60)$

\begin{tabular}{|l|l|c|c|}
\hline \multirow{2}{*}{ Variables } & \multicolumn{2}{|c|}{ Sample } \\
\cline { 2 - 4 } & Frequency & $\%$ \\
\hline \multirow{4}{*}{ Age } & 25 and less & 9 & $15 \%$ \\
\cline { 2 - 4 } & From 26 to 35 & 21 & $35 \%$ \\
\cline { 2 - 4 } & From 36 to 45 & 22 & $36.7 \%$ \\
\cline { 2 - 4 } & From 46 to 55 & 5 & $8.3 \%$ \\
\cline { 2 - 4 } & 55 and above & 3 & $5 \%$ \\
\cline { 2 - 4 } & Total & 60 & $100 \%$ \\
\hline \multirow{4}{*}{ Yevel of education } & Bachelor's degree & 15 & $25 \%$ \\
\cline { 2 - 4 } & Diploma and less & 11 & $18.3 \%$ \\
\cline { 2 - 4 } & Master's degree & 25 & $41.7 \%$ \\
\cline { 2 - 4 } & Ph.D. & 9 & $15 \%$ \\
\cline { 2 - 4 } & Total & 60 & $100 \%$ \\
\hline \multirow{5}{*}{} & Less than one year & 8 & $3.3 \%$ \\
\cline { 2 - 4 } & From 1 to 5 years & 20 & $33.3 \%$ \\
\cline { 2 - 4 } & From 6 to 10 years & 21 & $35 \%$ \\
\cline { 2 - 4 } & From 11 and over & 11 & $18.4 \%$ \\
\cline { 2 - 4 } & Total & 60 & $100 \%$ \\
\hline
\end{tabular}

Table (1) shows that the sample is representative. While the age group ( 36 to 45 years) was ranked first, whereas ( 55 and above) was ranked last. Concerning education, the master's degree was ranked first, while the Ph.D. degree was ranked last. In the years of experience, (6-10 years) was ranked first, whereas (less than one year) was ranked last.

\subsection{Instrumentation}

After reviewing the relevant literature, the author designed a questionnaire to explore Saudi women's perception of the "Qiyadat" leadership program and highlight the main features that support the development of leadership programs offered to Saudi women to ensure their proper participation in the execution of the Saudi Vision 2030. The questionnaire contained eight domains: Demographic information, program content, leadership competencies, leadership challenges, source of support, program success requirements, understanding the Saudi vision 2030, and the execution of the Saudi Vision 2030. Table 2 presents the domains of the questionnaire.

Table 2: Survey questionnaire description

\begin{tabular}{|l|l|l|}
\hline Section & Factor & Description \\
\hline A. & Demographics & Four questions: \\
& & 1- Age: 5 response groups \\
& & Education: 4 response groups \\
& & Experience: 5 response groups \\
\hline B. & Training program content & 12 statements (items) \\
& & 5-point scale \\
& & 1= Strongly disagree \\
& Leadership competencies & 5 Strongly agree \\
\hline C. & & 10 statements (items) \\
& & 5-point scale \\
& & 1= Strongly disagree \\
& Women leadership challenges & 6 Strongly agree \\
\hline D. & & 5-point scale \\
& & 1= Strongly disagree \\
& & 5= Strongly agree \\
\hline
\end{tabular}




\begin{tabular}{|l|l|l|}
\hline Section & Factor & Description \\
\hline E. & Source of support & 6 statements (items) \\
& & 5-point scale \\
& & 1= Strongly disagree \\
& & 5 Strongly agree \\
\hline F. & Program success requirements. & 6 statements (items) \\
& & 5-point scale \\
& & 1= Least important \\
& & 5= Most important \\
\hline G. & Understanding the Saudi Vision 2030 & 11 statements (items) \\
& & 5-point scale \\
& & 1=Strongly disagree \\
& & 5= Strongly agree \\
\hline H. & Execution of the Saudi Vision 203 & 5-point scale \\
& & 1= Strongly disagree \\
& & 5= Strongly agree \\
\hline
\end{tabular}

Table (2) shows that the questionnaire consisted of (57) items that were assigned into different factors: Content (12 items), competencies (10 items), challenges (6 items), support factors (6 items), success requirement (6 items), Understanding the Saudi Vision 2030 (11 items), and the execution of the Saudi Vision 2030 (6 items). Some factors were on a five-point Likert scale ( $1=$ strongly disagree, $5=$ strongly disagree) except for the program success requirement which followed the 5 -point scale ( $1=$ least important, $5=$ most important).

\subsection{Validity}

To verify the content validity of the questionnaire, it was reviewed by a panel of five specialists from academia working in management and human resources development at Princess Nourah Bint Abdulrahman University. Based on the feedback of the reviewers, appropriate adjustments were made. The correlation coefficient was used to calculate the internal validity between the score of each domain and the total score of the questionnaire by applying the tool to a pilot sample of (10) employed women, as shown in table (3).

Table (3): The validity of the questionnaire between the score of each domain and the total score of the questionnaire $(N=10)$

\begin{tabular}{|c|c|}
\hline \multicolumn{2}{|c|}{ Correlation coefficients between the score of each domain and the total score of the questionnaire } \\
\hline Correlation coefficient & $0.71^{* *}$ \\
\hline \multicolumn{2}{|l|}{ Leadership competencies } \\
\hline Correlation coefficient & $0.68^{* *}$ \\
\hline \multicolumn{2}{|l|}{ Leadership challenges } \\
\hline Correlation coefficient & $0.74^{* *}$ \\
\hline \multicolumn{2}{|l|}{ Sources of support } \\
\hline Correlation coefficient & $0.77^{* *}$ \\
\hline \multicolumn{2}{|l|}{ Program success requirements } \\
\hline Correlation coefficient & $0.89^{* *}$ \\
\hline \multicolumn{2}{|l|}{ Understanding the Saudi Vision 2030} \\
\hline Correlation coefficient & $0.89^{* *}$ \\
\hline \multicolumn{2}{|l|}{ Execution of the Saudi Vision 2030} \\
\hline Correlation coefficient & $0.88^{* *}$ \\
\hline
\end{tabular}

$\left.{ }^{* *}\right)$ Significant at the level of 0.01 
Table (3) illustrates that the correlation coefficients between the score of each domain and the total score of the questionnaire were (o.71) for the first domain, (o.68) for the second domain, (0.74) for the third domain, (0.77) for the fourth domain, (o.89) for the fifth and sixth domains, and (o.88) for the seventh domain. All coefficients are statistically significant at the level of (o.o1), suggesting the high internal validity of the questionnaire and its domains.

\subsection{Reliability}

The author used Cronbach's alpha to calculate the reliability of the tool, as shown in table (4).

Table (4): Reliability values of the research instrument and its domains

\begin{tabular}{|l|c|}
\hline Domains & Cronbach's Alpha \\
\hline Program content & $.88^{* *}$ \\
\hline Leadership competencies & $.94^{* *}$ \\
\hline leadership challenges & $.68^{* *}$ \\
\hline Sources of support & $.77^{* *}$ \\
\hline Program success requirements & $.83^{* *}$ \\
\hline Understanding the Saudi Vision 2030 & $.82^{* *}$ \\
\hline Execution of the Saudi Vision 2030 & $.84^{* *}$ \\
\hline Total & $.95^{* *}$ \\
\hline
\end{tabular}

$\left({ }^{* *}\right)$ Significant at the level of 0.01

Table (4) shows that all reliability coefficients of the instrument and its domains are significant at the level of 0.01 , suggesting its high reliability.

\subsection{Statistical analysis}

The author analyzed the data using SPSS and the following statistical methods: The Pearson correlation coefficient, Cronbach's alpha, arithmetic mean, standard deviation, and one way ANOVA.

\section{Results}

The data collected through the questionnaire were analyzed in the light of the three research questions. Separate analyses were conducted for each question.

1. What are the participants' perceptions of leadership in the light of the women's leadership program offered by Misk Foundation?

Table (5): The mean, standard deviation, and ranking of the leadership domains $(N=60)$

\begin{tabular}{|c|l|c|c|c|}
\hline No. & Domains & Mean & Std. Deviation & Ranking \\
\hline 1 & Program content & 3.45 & 0.72 & 7 \\
\hline 2 & Leadership competencies & 3.77 & 0.91 & 5 \\
\hline 3 & Leadership challenges & 3.50 & 0.61 & 6 \\
\hline 4 & Sources of support & 3.73 & 0.67 & 4 \\
\hline 5 & Program success requirements & 4.36 & 0.79 & 2 \\
\hline 6 & Understanding the Saudi Vision 2030 & 4.81 & 0.77 & 1 \\
\hline 7 & Execution of the Saudi Vision 2030 & 4.33 & 0.58 & 3 \\
\hline & Total & 3.99 & 0.72 & \\
\hline
\end{tabular}

Table (5) shows that the perceptions of the participants of leadership in the light of the women's leadership program offered by Misk Foundation were largely positive with an arithmetic mean of (3.99). 
The domain of (Understanding the Saudi Vision 2030) was ranked first with an arithmetic mean of (4.81), whereas the domain of (program content) was ranked last with an arithmetic mean of (3.45).

2. Is there a correlation between the participants' perceptions of leadership and the seven domains of the questionnaire (the leadership program content, leadership competencies, leadership challenges, sources of support, program success requirements, understanding the Saudi Vision 2030, and execution of the Saudi Vision 2030)?

Table (6): The correlation coefficients between the participants' perceptions of leadership and the seven variables of the questionnaire $(N=60)$

\begin{tabular}{|l|c|c|c|}
\hline \multirow{2}{*}{ Domains } & \multicolumn{3}{|c|}{ Participants' perceptions of leadership } \\
\cline { 2 - 4 } & Correlation & Sig & Type of Sig \\
\hline Program content & $0.93^{* *}$ & 0.00 & Statistically significant \\
\hline Leadership competencies & $0.92^{* *}$ & 0.00 & Statistically significant \\
\hline Leadership challenges & $0.65^{* *}$ & 0.00 & Statistically significant \\
\hline Sources of support & $0.98^{* *}$ & 0.00 & Statistically significant \\
\hline Program success requirements & $0.97^{* *}$ & 0.00 & Statistically significant \\
\hline Understanding the Saudi Vision 2030 & $0.97^{* *}$ & 0.00 & Statistically significant \\
\hline Execution of the Saudi Vision 2030 & $0.98^{* *}$ & 0.00 & Statistically significant \\
\hline
\end{tabular}

Table (6) shows that:

- There is a statistically significant positive correlation at the level of (o.o1) between the participant's perceptions of leadership and the first domain (program content) that rates (o.93), suggesting a very strong correlation between the perceptions and program content.

- There is a statistically significant positive correlation at the level of (o.o1) between the participant's perceptions of leadership and the second domain (leadership competencies) that rates (0.92), suggesting a very strong correlation between the perceptions and leadership competencies.

- There is a statistically significant positive correlation at the level of (o.o1) between the participant's perceptions of leadership and the third domain (leadership challenges) that rates (o.65), suggesting a very strong correlation between the perceptions and leadership challenges.

- There is a statistically significant positive correlation at the level of (o.o1) between the participant's perceptions of leadership and the fourth domain (sources of support) that rates (o.98), suggesting a very strong correlation between the perceptions and the sources of support.

- There is a statistically significant positive correlation at the level of (o.o1) between the participant's perceptions of leadership and the fifth domain (program success requirements) that rates (o.97), suggesting a very strong correlation between the perceptions and program success requirements.

- There is a statistically significant positive correlation at the level of (o.o1) between the participant's perceptions of leadership and the sixth domain (understanding the Saudi Vision 2030) that rates (0.97), suggesting a very strong correlation between the perceptions and understanding the Saudi Vision 2030.

- There is a statistically significant positive correlation at the level of (o.o1) between the participant's perceptions of leadership and the seventh domain (execution of the Saudi Vision 2030) that rates (0.98), suggesting a very strong correlation between the perceptions and the execution of the Saudi Vision 2030.

3. Are there statistically significant differences between the participants in their perceptions of leadership in the light of the women's leadership program offered by Misk Foundation according to the years of experience? 
Table (7): One-way ANOVA analysis of the participants according to the years of experience $(N=60)$

\begin{tabular}{|l|c|c|c|c|c|c|}
\hline Variables & Source of Variance & Sum of Squares & df & Mean Square & F & Sig. \\
\hline \multirow{3}{*}{ Perceptions of leadership } & Between Groups & 1074.667 & 3 & 358.222 & 1.017 & .392 \\
\cline { 2 - 6 } & Within Groups & 19720.266 & 56 & 352.148 & & \\
\cline { 2 - 6 } & Total & 20794.933 & 59 & & & \\
\hline
\end{tabular}

Table (7) shows no statistically significant differences between the participants' perceptions of leadership according to the years of experience. This finding highlights the ability of the Misk foundation's program to have positive perceptions among all participants regardless of the years of experience.

\section{Discussion}

Data analyses yielded several findings. A key result of the questionnaire is that the participants have a high level of perception of leadership. Their high awareness can be attributed to attending the leadership development program offered by Misk foundation. This finding agrees with the results of Hacifazlığlu (2010), Hopkins et al. (2008), and Rapanta and Badran (2016) that there is a need for coaching and mentoring women to obtain leadership positions. Thus, having a clear understanding and high expectations toward leadership is important for women to reach their potential.

The participants obtained high scores on their views concerning program competencies in the light of the leadership development program offered by Misk foundation. They are employed women and well experienced in these competencies during their education or work experience, especially skills, such as problem-solving, generating new strategies, and commitment as highlighted by different scholars, including Al-Olyan (2016) and Harris and Leberman (2012). Similarly, Dragoni, Park, Soltis, and Forte-Trammell (2014) and Rai and Singh (2013) suggested developing leadership competencies by integrating learning experiences, participation in giving feedback, improving role knowledge, and promoting high potentials' exposure.

The literature explored various challenges that women in leadership positions might face during their journey; the participants have high perceptions of leadership challenges competencies. Biological challenges in the form of maternity and the traditional role of women are the prime challenges consistent with Schwartz (1989); Saudi culture enables women to sacrifice their careers to maintain their maternity and traditional roles. These results confirmed the participants' agreement on the professional challenge as a major concern of women in leadership roles that are consistent with Jones and Solomon (2019). However, the participants significantly agreed on the absence of formal exclusion as a challenge contradicting those of Jones and Solomon (2019) who emphasized that formal exclusion is a major challenge for leader women. The absence of the major exclusion for Saudi women leader's links to the establishment and benefit of new regulations that women have secured, including inequality issues and the consideration of women as an equal part of the workforce as men. Furthermore, the findings confirm those by Almansour and Kempner (2016) who noted findings related to women's limited participation in academic occasions, including conferences due to family obligations, international travel, and cultural issues. Abalkhail (2017) Hodges (2017) also asserted that women had limited opportunities to take part in meetings due to the exclusion of women deans from the decision-making process, which constituted obstacles in the higher education context. This finding is attributed to social, religious, cultural, and organizational factors.

The design of any training program, including leadership programs, must consider the different aspects of culture and social environment, the characteristics of the targeted groups, and the political environment where the program is delivered. The participants agreed on specific items that ensure leadership program success while focusing on women's leadership capabilities. This finding agrees with the results of Schwartz (1997) who asserted that women need special skills to achieve their leading roles. Moreover, Vinnicombe and Singh (2003) assured that the leadership development process for 
women is not the same as that of men. The participants from the treatment group were also concerned with the clarity of the leadership program's mission, vision, objectives, and enforcing values, supporting the results of Allio (2005) and Trinidad and Normore (2005). Additionally, Krystal and Brue (2016) highlighted that providing experiential learning and network development are essential for leadership program success. The results also agreed with Debebe (2011) who asserted that learning from the shared experiences of female leaders in a safe environment to internalize confidence for successful leaders is an important factor for leadership programs success.

As extensively discussed in the literature, support is a prime factor that helps individuals face and mitigate challenges and overcome barriers that women encounter, including organizational and socioeconomic barriers (Kalaitzi, Cheung, Hiligsmann, Babich, and Czabanowska, 2019). In this study, the participants indicated a higher level of support. They reported that support for their exploration of leadership stems from family, colleagues, and friends as the prime support. However, the participants reported limited or no support from government and private agencies. This finding is consistent with the results of Jones and Solomon (2019). Similarly, The KPMG Women's Leadership Study (2019) found that women who perceived themselves as "smart" and received support from family members, teachers, and female role models were more apt to be successful leaders. This finding is consistent with Hamdan and Al Hattami (2018) and Krause (2017) who asserted that participants' success was due to encouragement and recognition by others.

Since the Saudi Vision 2030 has paid great concern to human power as a major factor in the execution and success of achieving the vision goals, the Saudi government has used massive media sources to announce and introduce the vision to the public locally and internationally. Women, by the support of the Saudi government, are supported through modifying various regulations and wider career opportunities to ensure their participation in the execution of the vision. The participants showed confidence in their abilities to execute the vision explained by their extensive exposure to the vision through not only media but also their careers where they were encouraged to attend the leadership program to help them play their leading roles. Allied to their self-efficacy in achieving the vision, the participants also indicated their ability to contribute and willingness to improve personal, family, and society levels, in addition to confidence in participation and making decisions. This finding agrees with Al Ghamdi (2016) who concluded that female leaders need to be psychologically empowered in Saudi Arabia to be capable of achieving successes and goals. It is also consistent with NcNae and Vali (2015) that reported that cultural support empowers women to trust their abilities and access leadership roles.

\section{Recommendations}

In the light of the findings, it is beneficial to support the country's efforts to empower women and develop partnerships with the public as well as private sectors to implement policies that target working women's access to leading positions in all life spheres. Policymakers and stakeholders should address women's needs and help overcome challenges facing women's empowerment and gender equity within the Saudi context. It is important to have partnerships with governmental, international, and national organizations for the sustainable development of leadership. Gender specialists must adopt policies and regulations to grant women more opportunities for education, empowerment, and employment. It is worthwhile if course designers can integrate materials of leadership courses and programs and professional development programs. Leadership training institutions can make use of the results when designing training programs and materials that should consider all areas discussed in the research. Finally, the government should provide training and workshops for men and women in society to raise awareness of women's rights and responsibilities.

The present study utilized the analytical descriptive design to explore employed women's perceptions of leadership in the light of a leadership program. Future research can utilize the quasiexperimental design to investigate the effectiveness of using leadership programs in developing leadership awareness. Implementing mixed-method approach studies that include qualitative and 
quantitative instruments and longitudinal studies might increase the generalizability of the results to other contexts. It is also recommended for future studies to expand the domains and themes assessed about leadership to gain valuable data. More research should investigate the impact of the existing leadership programs on the skills and capacities of female leaders who received the training and how does it affect their workplace. A comparative study to compare men's and women's experiences and perceptions is highly recommended. The effect of other demographic variables e.g. gender, age, and education level on perceptions of leadership should be investigated. The author also recommends that the current study be replicated on a larger sample to seek further verification of the findings.

\section{Conclusion}

To evaluate employed women's expectations and perceptions of leadership, the author applied a questionnaire to 6o employed women that accomplished a leadership development program "Qiyadat" offered by Misk Foundation. The questionnaire was designed to collect data on eight domains: Demographic information, program content, leadership competencies, leadership challenges, source of support, program success requirements, understanding the Saudi vision 2030, and the execution of the Saudi Vision 2030. The findings showed that the participants have high perceptions of leadership due to the leadership development program offered by Misk Foundation. Additionally, there was a positive correlation between the participants' perceptions of leadership and the seven variables of the questionnaire (the leadership program content, leadership competencies, leadership challenges, sources of support, the program success requirements, understanding the Saudi Vision 2030, and execution of the Saudi Vision 2030). The results also indicated that there were no statistically significant differences between the participants in their perceptions of leadership in the light of the women's leadership program offered by Misk Foundation according to the years of experience variable.

Several limitations of the present study were encountered and need to be acknowledged. The study is limited to 60 employed women. The study is also limited by the instrument used for collecting data; the questionnaire as only quantitative data were gathered and analyzed. Since the "Qiyadat" leadership program is one of the principal programs for qualifying leaders in Saudi Arabia, employed women's perceptions of leadership were investigated. Only women participated in this study, so the study is restricted to the female perspective on leadership.

\section{Acknowledgment}

The researcher would like to thank the Center for Promising Research in Social Research and Women's Studies and Deanship of Scientific Research at Princess Nourah Bint Abdulrahman University for funding this research project under Grant no. [3807].

\section{References}

Abalkhail, J. (2017). Women and leadership: Challenges and opportunities in Saudi higher education. Career Development International, 22(2), 165-83. doi.org/10.1108/CDI-03-2016-0029.

Akingbola, K. (2013). Resource-based view (RBV) of unincorporated social economy organizations. Canadian Journal of Nonprofit and Social Economy Research, 4(1), 66-85.

Al Alhareth, Y., Al Dighrir, I. \& Al Alhareth, Y. (2015). Review of women's higher education in Saudi Arabia. American Journal of Educational Research 3(1), 10-15. DOI: 10.12691/education-3-1-3.

Al-Ahmadi, H. (2011). Challenges facing women leaders in Saudi Arabia. Human Resource Development International, 14 (2), 149-166. DOI: 10.1080/13678868.2011.558311.

Al-Asfour, A., Tlaiss, H., Khan, S., \& James, R. (2017). Saudi women's work challenges and barriers to career advancement. Career Development International, 22(2), 184-99. doi.org/10.1108/CDI-11-2016-0200.

Al Ghamdi, A. (2016). The empowerment of academic women leaders at Saudi universities and its relationship to their administrative creativity (Doctoral dissertation, Western Michigan University, Michigan). Retrieved from https://scholarworks.wmich.edu/dissertations/2484/. 
Allio, R.J. (2005). Leadership development: Teaching versus learning. Management Decision, 43 (7/8), 1071-1077. Doi.org/10.1108/00251740510610071.

Almansour, S. \& Kempner, K. (2016). The role of Arab women faculty in the public sphere. Studies in Higher Education, 41(1), 874-86. DOI: 10.12691/education-5-9-11.

Almenkash, S., Abdulaziz, M., Shaman, A., Haijan, A., and Dagsh, N. (2007). The issue of management women/men in higher education institutions for girls. Riyadh: King Abdullah Institute for Research Consultancy Studies.

Al-Olyan, M. (2016). Competency of women leaders and its relation to human resources management from the viewpoint of females employees of King Faisal Specialist Hospital and Research Centre in Riyadh (Master's thesis). Naif Arab University for Security Sciences, Riyadh, KSA.

Alomair, M. (2015). Female leadership capacity and effectiveness: A critical analysis of the literature on higher education in Saudi Arabia. International Journal of Higher Education, 4(4), 81-93. Doi:10.5430/ijhe.v4n4p81.

Alotaibi, F., Cutting, R. \& Morgan, J. (2017). A critical analysis of the literature in Women's leadership in Saudi Arabia. International Journal of Business Administration and Management Research, 3 (1), 29-36.DOI: 10.24178/ijbamr.2017.3.1.29.

Al-Shamrani, M. (2015). An empirical study of male and female leadership styles in a segregated work environment in the Kingdom of Saudi Arabia (Doctoral dissertation). University of Hull, Hull, UK.

Al-Sudairy, H. (2017). Modern woman in the Kingdom of Saudi Arabia: Rights, challenges and achievements. Newcastle-upon-Tyne: Cambridge Scholars Publishing.

Alwazzan, L. \& Al-Angari, S. (2020). Women's leadership in academic medicine: a systematic review of extent, condition and interventions. BMJ Open, 10, e032232. doi: 10.1136/bmjopen-2019-032232.

Creswell, J. (2013). Qualitative inquiry and research design: Choosing among five approaches ( $3^{\text {rd }}$ ed.). Thousand Oaks, CA: Sage Publications, Inc.

Cook, S. (2012). Women presidents: Now 26.4\% but still underrepresented. Women in Higher Education, 21(5), 1-3. https://doi.org/10.1002/whe.10322.

Dannels, S., Yamagata, H., McDade, S., Chuang, Y., Gleason, K., McLaughlin, J.... Morahan, P. (2008). Evaluating a leadership program: A comparative, longitudinal study to assess the impact of the Executive Leadership in Academic Medicine (ELAM) Program for Women. Academic Medicine, 83 (5), 488-495. Doi: 10.1097/ACM.obo13e31816be551.

Debebe, G. (2011). Creating a safe environment for women's leadership transformation. Journal of Managerial Education, 35(5), 679-712. doi:10.1177/1052562910397501.

Dragoni, L., Park, H., Soltis, J., \& Forte-Trammell, S. (2014). Show and tell: How supervisors facilitate leader development among transitioning leaders. Journal of Applied Psychology, 99(1), 66-86. doi:10.1037/aoo34452

Ehrhart, M. \& Klein, K. (2001). Predicting follower preferences for charismatic leadership: The influence of follower values and personality. Leadership Quarterly, 12(2), 153-179.

Ely, R., Ibarra, H. \& Kolb, D. (2011). Taking gender into account: Theory and design for women's leadership programs. Academy of Management Learning E Education, 10(3), 474-493. doi:10.5465/amle.2010.0046.

General Authority for Statistics. (2019). Labor market bulletin methodology. Saudi Arabia: General Authority for Statistics.

Hacıfazlıoğlu, Ö. (2010). Entry and transition to academic leadership: Experiences of women leaders from Turkey and the U.S. Educational Sciences: Theory \& Practice, 10 (4), 2257-2273.

Hamdan, A. \& Al Hattami, A. (2018). The impact of a leadership program on Saudi University students: Perception of leadership skills. Journal of Education and Learning, 12 (2), 253-261.DOI.10.11591/edulearn.v12i2.5840.

Hamdar, B., Massoud, R. \& Farha, G. (2013). Female leadership: An exploratory research from Lebanon. American Journal of Scientific Research, 86, 28-52.

Harris, C. \& Leberman, S. (2012). Leadership development for women in New Zealand universities: Learning from the New Zealand Women in Leadership Program. Advances in Developing Human Resources, 14 (1), $28-44$. Doi.org/10.1177/1523422311428747.

Hodges, J. (2017). Cracking the walls of leadership: Women in Saudi Arabia. Gender in Management: An International Journal, 32(1), 34-46. DOI: 10.1108/GM-11-2015-0106.

Hopkins, M., O'neil, D., Passarelli, A. \& Bilimoria, D. (2008). Women's leadership development strategic practices for women and organizations. Consulting Psychology Journal: Practice and Research, 60 (4), 348-365. Doi.org/10.1037/aoo14093.

Howard, E. (2019). Effective support for women's leadership in the Pacific: Lessons from the evidence. USA: Department of Pacific Affairs.

Jones, M. \& Solomon, J. (2019). Challenges and supports for women conservation leaders. Conservation Science and Practice, 1 (6), 1-11. Doi.org/10.1111/csp2.36. 
Kalaitzi, S., Cheung, K., Hiligsmann, M., Babich, S. \& Czabanowska, K. (2019). Exploring women healthcare leaders' perceptions on barriers to leadership in Greek context. Frontiers in Public Health, 7 (68), 1-9. doi.org/10.3389/fpubh.2019.00o68.

Kauser, S. \& Tlaiss, H. (2011). Middle Eastern women manager: Participation, barriers, and future prospects. Journal of International Business Economy, 12(1), 35-56.

KPMG Women's Leadership Study (2019). Moving women forward into leadership roles. Retrieved from KPMG.com/WomensLeadership.

Krause, S. (2017). Leadership: Underrepresentation of women in higher education (Doctoral dissertation). Northcentral University, California.

Krystal, B. \& Brue, S. (2016). Experiences and outcomes of a women's leadership development program: A phenomenological investigation. Journal of Leadership Education, 15 (3), 75-97. DOI: 10.12806/V15/I3/R2.

Martin, S., Jahani, S. \& Rosenblatt, K. (2016). Educating young women to be global leaders: A model. VOLUNTAS: International Journal of Voluntary and Nonprofit Organizations, 27 (3), 1494-1511. doi.org/10.1007/s11266-0169702-7.

Metcalfe, B. (2006). Exploring cultural dimensions of gender and management in the Middle East. Thunderbird International Business Review, 48 (1), 93-107. DOI: 10.1002/tie.20087.

Ministry Of Education. (2017). Electronic services. Retrieved from: https://www.moe.gov.sa/ar/Pages/default.

Mohammed bin Salman Foundation (Misk) (2019). About Misk. Riyadh/ Kingdom of Saudi Arabia. Retrieved from https://www.misk.org.sa/\#about

Mohammed bin Salman Foundation (Misk) (2018). Qiyadat MISK Program. Retrieved from https://misk.org.sa/en/services/qiyadat2018-en/

NcNae, R. \& Vali, K. (2015). Diverse experiences of women leading in higher education: Locating networks and agency for leadership within a university context in Papua New Guinea. Gender and Education, 27 (3), 288303. Doi.org/10.1080/09540253.2015.1027669.

Pfeffer, J. \& Salancik, G. (1978/2003). The external control of organizations: A resource dependency perspective. Stanford, CA: Stanford University Press.

Poltera, J. (2019). Exploring examples of women's leadership in African contexts. Agenda: Empowering Women for Gender Equity, 33 (1), 3-8. doi.org/10.1080/10130950.2019.1602977.

Rai, H., \& Singh, M. (2013). A study of mediating variables of the relationship between $360^{\circ}$ feedback and employee performance. Human Resource Development International, 16(1), 56-73. doi:10.1080/13678868.2012.740797.

Rapanta, C. \& Badran, D. (2016). Supporting Emirati females leadership skills through teaching them how to debate: Design, assessment, and considerations. The International Journal of Management Education, 14 (2), $133-145$.

Schwartz, F. (1989). Management women and the new facts of life. Harvard Business Review, 4 (5), 65-76. doi.org/10.1108/eumooooooooo1789.

Schwartz, R. (1997). Reconceptualising the leadership role of women in higher education: A brief history on the importance of deans of women. Journal of Higher Education, 68 (5), 502-522. doi.org/10.2307/2959944

Tajfel, H. \& Turner, J. (1985). The social identity theory of intergroup behavior. In: S. Worchel \& W. Austin (Eds.), Psychology of intergroup relations (2 ${ }^{\text {nd }}$ ed.), pp.7-24. Chicago: Nelson-Hall.

The Council of Economic and Development Affairs (CEDA). (2016). Saudi Vision 203o. Riyadh/ Kingdom of Saudi Arabia. Retrieved from https://vision2030.gov.sa/en/node/36o\#.

Trinidad, C. \& Normore, A. (2005). Leadership and gender: A Dangerous liaison? Leadership E Organization Development Journal, 26 (7), 574-590. doi.org/10.1108/01437730510624601.

Vinnicombe, S. \& Singh, V. (2003). Women-Only management training: An essential part of women's leadership development. Journal of Change Management, 3(4), 294-306. doi.org/10.1080/714023846.

Walton, O. (2012). Helpdesk research report: Measuring and evaluating women's leadership. UK: Governance and Social Development Resource Center. Retrieved from: https://gsdrc.org/publications/measuring-andevaluating-womens-leadership/ 